\title{
TEACHING LEGAL ETHICS
}

\author{
SUSAN BURNS*
}

There is a growing body of literature in the United States and Canada which examines the place of instruction in legal ethics in the broader context of legal education. To date, there has been little consideration of this subject in Australian writing on legal education. This paper reviews the more recent literature in the area, particularly in relation to the need for instruction in legal ethics, the forms of existing tuition and the alternative course structures and teaching methodologies.

\section{WHAT IS LEGAL ETHICS?}

Writers use the terms "legal ethics", "professional responsibility" and "legal profession" more or less synonymously. Teaching legal ethics is concerned with imparting to students a critical understanding of the legal profession, its structures, its roles and responsibilities, the roles and responsibilities of lawyers in their provision of professional services and the individual student's own values and attitudes. It includes an examination of what the legal profession does and ought to do. ${ }^{1}$

Legal ethics involves teaching students about the disciplinary rules regulating the legal profession. These are frequently statute based and usually enforced by punitive sanctions. Legal ethics is also concerned with an examination of the personal values or moralities of individual lawyers and issues such as the legitimacy of requiring lawyers to perform roles that conflict with personal values. In this paper the term "legal ethics" is used in a broad sense to encompass consideration of the disciplinary rules and broader issues of morality and philosophy. 


\section{TEACHING LEGAL ETHICS}

Most of the writing in this area considers the threshold question of whether it is appropriate that legal ethics be taught at all. The approach of writers to this question can be related in part to their view of what legal ethics comprises.

Most writers raise as an objection to the teaching of legal ethics the view that such courses amount to exercises in or attempts at moral indoctrination of the students. This, of course, presupposes that the course content is limited to moral/philosophical aspects, and that the students are malleable enough to be indoctrinated. Critics assert that moral or ethical conduct is a personal matter gained through early socialisation and that, as a consequence, education in legal ethics at a time when students are preparing for entry into the profession comes too late to make any difference to their character. As one commentator expressed the concern, legal ethics, "like politeness on subways ... or fidelity in marriage" cannot be acquired through course assignments in professional schools. $^{2}$

Other critics argue that it is inappropriate for faculty members or members of the profession to impose their morals on others. They argue that instruction in legal ethics can be a demoralising experience for students if teachers impose their values and penalise students for holding views, beliefs and opinions which do not coincide with those of their instructors. Additionally, critics assert that if educators attempt to impose their morals and ethical beliefs on others, a course in legal ethics can "lapse into a form of value clarification that erodes values,"3 that is, the beliefs and values of the students are supplanted by those of the instructor.

Proponents of courses in legal ethics state that the arguments against legal ethics apply equally to teaching many other courses. Although there is always the potential for a course to be weighted too heavily in favour of a teacher's own views:

We will not eliminate the difficulty by eliminating ethics. The answer rather is to educate the educators. A well structured component on ethics can help counter the interplay of naive positivism and radical scepticism that often dominates professional culture. ${ }^{4}$

Finally, critics assert that a course in legal ethics can inadvertently foster cynicism in students. They argue that if students are presented consistently with instances of regulatory 
failures and ethical dilemmas with no apparent solution, they may develop a scepticism about the profession and the role that instruction in legal ethics can play.

The consensus amongst recent academic writings is that instruction in legal ethics is desirable because:

[although it is] ... unlikely to lure wayward souls to the path of righteousness ... it can increase recognition of ethical issues, enhance skills in ethical analysis and build awareness of the structural conditions and regulatory failures that contribute to problems in professional life. ${ }^{5}$

Instruction in legal ethics draws students' attention to the existence of values, introduces students to the ethical dimensions of the roles they will have as professionals and stimulates the capacity for and willingness to engage in reflective judgment. ${ }^{6}$ As one commentator has stated, the acknowledgement that legal education can do "only a little" to affect professional behaviour "does not justify doing nothing."7

Since lawyers are potentially in a very difficult situation because of the competing duties they may face as a result of their position in society, it has been suggested that a grounding in legal ethics may help practitioners to avoid any conflicts or other ethical dilemmas as they arise. If an individual has an insight into the nature of the forces with which he or she is struggling and has had practice in working out solutions for such conflicts as a part of his or her legal education then that person is better prepared to overcome a conflict when it arises. ${ }^{8}$

\section{SHORTCOMINGS OF CURRENT EDUCATION IN LEGAL ETHICS}

A recent comprehensive study of the teaching of legal ethics in Canada identified the following shortcomings in existing instructions in legal ethics:

(a) a lack of commitment to professional responsibility instruction;

(b) a lack of co-ordination regarding professional responsibility instruction among the various providers of legal education;

(c) inappropriate or incomplete instructional objectives;

(d) the use of ineffective teaching methodologies;

(e) little or no curriculum planning with respect to professional 


\section{responsibility instruction;}

(f) lack of resources; and

(g) lack of educational and institutional infrastructure. ${ }^{9}$

\section{OBJECTIVES IN TEACHING LEGAL ETHICS}

A leading proponent of teaching legal ethics has identified the following objectives as the key objectives in training students in legal ethics:

- to introduce students to the organisation of the legal profession, its structure and responsibilities;

- to inform students of various perspectives which have contributed to that organisation;

- to enable students to evaluate the organisation of the legal profession and its effectiveness in fulfilling its responsibilities;

- to introduce students to the responsibilities of lawyers in various professional roles and contexts;

- to enable students to identify responsibilities when they arise;

- to enable students to develop attitudes towards and values about the legal profession and professional responsibility;

- to enable students to engage in the process of ethical reasoning so as to be able to:

- evaluate the appropriateness of professional roles and their implications for the student;

- develop frameworks for evaluating professional obligations and selecting appropriate courses of action when these obligations come into conflict; and

- to enable students to conduct professional work in a competent, efficient, organised, professional manner. ${ }^{10}$

\section{DESIGNING A COURSE IN LEGAL ETHICS}

If we assume that it is desirable to teach law students legal ethics, the most appropriate and effective course structure must be determined. Clearly any course should be designed to overcome perceived shortcomings in existing courses, and to fulfil the identified objectives of instruction.

Course structure and teaching methodologies must be considered. Should instruction take place in a "once-only" course or should instruction occur throughout a student's legal education? 
Should instruction occur in a clinical setting or in a classroom? Course structures which have been employed include pervasive instruction where legal ethics issues are raised during substantive law courses, clinical courses, simulated practice and "stand-alone" courses. Methodologies which have been used to date include case studies (relating ethical problems to disciplinary hearings which have taken place before courts and tribunals), problem methods, Socratic instruction, discussion, videos and film presentations, cocurricular activities and lecture techniques. There are important timing issues which must be resolved, such as whether instruction should occur early in a student's law school experience, at a later stage of law school, after law school and before admission or post admission, or at several stages throughout a student's education.

\section{COURSE STRUCTURE}

\section{Pervasive Teaching}

The pervasive method of instruction in legal ethics consists of systematically teaching students about legal ethics issues as they arise in other substantive law subjects. This approach is intended to demonstrate to students that issues in legal ethics pervade all areas of the law and do not arise merely in discrete courses on legal ethics.

If a pervasive approach to teaching legal ethics is to be adopted, it is important that it be adopted by the entire law school faculty and be:

"considered a natural and integral component of instruction in procedural and substantive law." 11

Commentators suggest that it is important not to emphasise legal ethics issues constantly, as students are more likely to respond positively to training in legal ethics if ethics issues are raised only sporadically. The success of a pervasive approach to teaching legal ethics depends upon commitment of the faculty and willingness of the students to examine ethical issues and questions as they arise. By considering issues of legal ethics as they arise, it reinforces the notion that the ongoing consideration of ethical issues in practice is a crucial constituent of practice. Failure to address issues of legal ethics consistently throughout a law student's education marginalises their significance. If students see issues of legal ethics 
as a peripheral part of their legal education, they may well regard issues of legal ethics which arise during the tasks they perform in practice as peripheral to that practice.

The pervasive method of teaching legal ethics is not without its critics. Commentators have noted the following issues as being problems associated with teaching legal ethics pervasively:

- Students may perceive a tension or conflict between the "concrete" subject matter of the substantive law subjects they are studying and the ethical issues which arise during the teaching of those subjects.

- Consideration of the legal ethics issues in a course requires a teacher to become more knowledgeable about issues, literature and guides and resolution of issues. Critics argue that teachers just will not have the time to prepare themselves adequately to teach legal ethics issues satisfactorily.

- The required long-term commitment and intensity required to retain legal ethics issues in a substantive law course are difficult to maintain.

- Unless the particular manner in which ethical issues are to be raised in a black letter law course has been determined at faculty level, there is no guarantee that a variety of legal ethics issues will be raised across the curriculum. If teachers devise their own course structures, consideration of ethical issues may be haphazard and unsystematic with some topics receiving too much coverage and some topics not enough coverage.

- There is difficulty monitoring subjects so as to be confident of attention to a broad range of ethical issues. Monitoring of subjects may be perceived by faculty members as an interference with academic independence.

- There is not sufficient time in substantive law subjects for ethics issues to be addressed comprehensively, and in the context of relevant theories. ${ }^{12}$

- In relation to ethical issues which cut across many substantive areas of law, such as confidentiality or honesty in negotiations, pervasive instruction may lead to shallow and repetitive treatment rather than treatment of a sufficient depth to impart in students an appreciation of the importance of an area and to assist students to develop a framework within which to address issues of legal ethics as they arise. 
- Lack of interest, on the part of both faculty members and students, as well as lack of experience in teaching pervasively may yield a coverage that is "superficial, uninformed, truncated or notable largely in its absence". ${ }^{13}$

One commentator who strongly favours instruction in legal ethics by the pervasive method believes that the problems are surmountable if some co-ordination can be achieved in the method and content of instruction. Co-ordination can assist in ensuring that repetition or overlap is kept to a minimum and can also minimise omissions. Finally, co-ordination of instruction can establish a set of core questions which can be addressed or examined from differing view points in a variety of courses. ${ }^{14}$

It is interesting to note that the American Bar Association House of Delegates has recently recommended that law schools, "weave ethical and professional issues into courses in both substantive and procedural fields.”15

\section{Clinical Instruction}

The clinical method of instruction in legal ethics has as its core direct student exposure to clients. The method is client-centred and depends upon the student taking responsibility for the representation of the client. The outcome for the client depends on the work undertaken by the student on the client's behalf. ${ }^{16}$

Clinical instruction involves students engaging in: the multitude of emotional reactions law practice situations generate. Such feelings are rarely confronted during the legal education process, with its heavy emphasis on rationality and the development of analytical skills. ${ }^{17}$

Students, in effect, perform the role of the lawyer. They are compelled to face the consequences of their actions, and in particular, the consequences of their failures and shortcomings. ${ }^{18}$

While some commentators perceive the advantages in a student performing the lawyer's role, and being responsible for the consequences of their actions, other commentators feel that the clinical method of instruction has its shortcomings. Although the clinical method may be successful in communicating the experience-based aspects of legal ethics, its usefulness in communicating the necessary substantive legal material (such as ethics principles, professional rules of conduct and the like) is 
doubtful. Other criticisms include the following:

- The service element of the undertaking is so important that instruction in legal ethics takes a "back seat."

- There are "serious moral, methodological, and practical problems" in attempting to teach the entire field of legal ethics in a clinical setting.

- Given that clinical instruction methods are of limited duration (usually one or two semesters) there is little control in the areas to which students are exposed, and even if students do get exposure to areas of legal ethics, the chances are that they will finish their course before they have the opportunity to resolve the issues that have arisen. The case will be passed to another student who in turn is disadvantaged because he or she has not been involved in the circumstances leading up to the issues emerging. ${ }^{19}$

- There is an underlying moral question surrounding the use of actual clients as a means to an end in training lawyers.

- The structure of the clinical method of instruction may be such that rather than a student having the opportunity to learn from his or her mistakes, a case is taken from the student before this mistake has been made. There is an inherent conflict between what is best for the client, and what is best for the education of the student.

In summary, the overriding concern about the clinical setting as a setting for instruction in legal ethics is that coverage may be superficial and ad hoc, depending as it does very largely on the cases that come before the clinics.

\section{Simulated Practice}

Critics of the clinical method of instruction assert that instruction by role play in a simulated practice setting will overcome all the objections to instruction in legal ethics through the clinical method. With clinical instruction methods there are:

real problems with instructor dominance, unpredictable substance (some issues will never arise), uncontrollable coverage, and relatively shortterm exposure (resulting in many of the ramifications of ethics choices being passed to the next student instead of being experienced by the acting student). ${ }^{20}$

On the other hand, although, “... long term simulations ... will 
not result in real outcomes for any client"21 simulations "have certainty of issue coverage, the likelihood that students will see the results of their own choice, and students exercising independent judgment and developing long term relationships with the various participants.” 22

A major proponent of simulation/role play as a method of legal ethics instruction advocates that the programme should fall within a comprehensive skills development (“CSD”) programme of one to two years' duration. During the CSD programme students work with other students, and with supervisors, dealing with the legal problems of simulated clients (played by real people). They have carriage of a matter from the stage of initial instructions to the stage of resolution of the "client's" problem. ${ }^{23}$

The CSD programme is purported to retain the best aspects of the articling system, combined with the best aspects of an academic atmosphere.

Simulations have all the advantages of clinical instruction methods, with none of the disadvantages:

Simulations, if well constructed, afford opportunities similar to those provided by in-house clinic situations to "learn by doing" and "learn by imitating”, which, activists correctly argue, teach moral judgment. Once students are put into a setting conducive to learning by doing and learning by imitating, teachers must concern themselves with what students do and whom they imitate. ${ }^{24}$

In a simulation, teachers have a greater opportunity to oversee "what students do and whom they imitate". Teachers devise the cases placed before students and oversee student conduct in the handling of their workload. Finally, instruction by simulation avoids the underlying moral question of using actual clients for the purposes of educating law students. If the same ends can be achieved using simulated clients, why should there be a need to use "real" clients? ${ }^{25}$

\section{Single Course}

Most existing law school education in legal ethics occurs in a single course, variously entitled "Introduction to Law", "Legal Profession", "Legal Ethics" or "Professional Responsibility”. Instruction is usually lecture or seminar based and may cover topics such as: 
- Doctrine - codes of conduct, relevant statutes, common law principles and rulings issued by the relevant professional body, covering topics such as:

- duty to the court

- duty to uphold the law

- duty to other counsel

- duty not to break the law

- duty not to assist others to break the law

- conflicts of interest

- personal ethics vis-a-vis professional role

- duty to represent the client

- confidentiality

- duty to the Law Society

- relationship with clients

- duty to be competent

- discrimination

- general ethical duties.

- History and sociology of the legal profession.

- Morality of the lawyer's role.

The most commonly taught subject matter in these single courses of instruction is doctrine, and especially the codes of conduct or professional rules governing behaviour.

It has been suggested that teaching rules alone is not enough. The criticism revolves around the notion that if students are taught the rules alone, without the philosophical and ethical issues which have given rise to those rules, students may form the view that legal ethics can be reduced to the making and following of rules. ${ }^{26}$

Not all ethical issues and dilemmas can be reduced to a set of rules. Students should be given as broad an instruction in all aspects of legal ethics as is possible, so that they are given a framework in which to deal with ethical dilemmas as they arise. Students should never be placed in a position where it is the doctrine alone in which they receive instruction. They should not be placed in a position where, if the doctrine does not exactly match the ethical dilemma they are facing, they do not know how to deal with the ethical issues before them. 
The most frequent criticism of single courses in legal ethics is that a single course carries with it the adverse implication that legal ethics is a relatively unimportant subject. Unlike courses in substantive law subjects which are relatively self-contained, issues of ethics pervade many if not all substantive law courses. To limit the consideration of ethical issues to one course limits the ability of students to recognise ethical issues when they arise in diverse areas of practice, as they are bound to do. The conclusion of one commentator seems apt:

The present practice of giving a single course seems about as logical as keeping a medical student in laboratories during the four years of medical school and then turning him out upon an innocent population after a l-hour course in "medical practice". He would assuredly be lost, and so would be his patients. ${ }^{27}$

\section{METHODOLOGIES}

\section{Case Studies}

Case studies have been described as a "poor primary resource" for instruction in legal ethics. ${ }^{28}$ Generally, case studies involve reviews of actual cases of misconduct which have been considered by disciplinary tribunals or courts. The method provides an opportunity for presentation of facts, and an illustration of the manner in which the problem has been resolved by the tribunal or court. Critics suggest that case studies do not provide an opportunity for discussion nor do they equip students with a technique for recognising and solving ethical dilemmas as they arise. However, case studies are considered useful as a secondary source to provide insight into the way disciplinary processes work by demonstrating the range of sanctions which may be imposed for a breach of prescribed standards of professional conduct. ${ }^{29}$

\section{Problem Methods}

Much of the existing education in legal ethics is conducted using the problem method. Students are presented with various hypothetical fact situations and are asked to explore the issues arising on the facts, using their knowledge of ethical and moral standards and the various applicable codes or rules which apply to the profession. The problem method has perceived advantages over 
the case study method in that it requires students to engage in deep consideration of the consequences of the facts before them. Unlike the case study method where students are aware of the ethical issues involved in a problem at the commencement of their consideration of the case, the problem method requires students to isolate the ethical issues which arise before they can go on to attempt to resolve the issues. In addition, using the problem method enables instructors to expose students to a wider range of issues, for example, ethical dilemmas which arise during negotiations. ${ }^{30}$ Some issues just do not arise in actual cases considered by disciplinary tribunals or courts.

\section{Socratic Instruction}

The Socratic method of instruction has as its focus the development of the cognitive skills of students. It is reputed to be effective as a means of clarifying feelings, behaviour and attitudes, at least for the student actively involved in discourse with the lecturer.

Faculty members should, if they are determined to use the Socratic method of instruction, know how to use the method successfully. Students often feel uncomfortable having to engage in discussions or debates with their instructors. Students may feel particularly reluctant to engage in discussion where their ethics or morals may be called into question. Socratic instruction should not be an exercise in students having to guess what the lecturer is thinking, and then being reprimanded or ridiculed when they guess incorrectly ${ }^{31}$ Socratic instruction is, apparently, most successful when it is conducted in relatively small groups, with few observers present. $^{32}$

\section{Discussion Method}

The discussion method of instruction in legal ethics is intended to result in "sharpened insight and sensitivity" in students. Participation in small group discussions concerning ethical issues is intended to provide an opportunity for students to engage personally in the resolution of ethical dilemmas which may, in turn, stimulate "more reflective moral reasoning". ${ }^{33}$

The discussion method, unlike traditional methods of ethics 
instruction which have required only passive learning, has the potential to "affect a development of cognitive skills requisite for principled learning." ${ }^{34}$ In addition, discussing issues of legal ethics at law school may impart in students an appreciation of the importance of discussing issues of legal ethics as they arise in practice and may encourage students to seek help from colleagues in resolving problems confronting them. ${ }^{35}$

\section{Video and Film Presentations}

Instruction in legal ethics by video and film presentation has several favourable aspects. Visual media have been found to arouse interest and capture student attention, both vital prerequisites to effective learning. The film medium may assist students, who have had little or no exposure to legal ethics issues, to grasp concepts more easily since ideas are conveyed by image and spoken word rather than by spoken or written word alone.

Criticisms of the use of film and video materials in legal ethics education include:

- the expense and difficulty involved in obtaining suitable materials for presentation;

- the expense involved in obtaining the necessary equipment to present the legal ethics materials;

- student intolerance of amateurishness in the material being presented;

- the risk that some students may not respond to the material and may remain passive and unaffected. ${ }^{36}$

\section{Co-Curricular Activities}

Co-curricular activities are activities with an education component that are not a formal part of the curriculum. Participation would usually be voluntary and attendance at cocurricular events may reinforce issues of legal ethics raised on other occasions. Possible events include:

(a) outside speaker programmes involving members of the judiciary and the profession and from other academic areas such as philosophy;

(b) career oriented panels;

(c) book discussions; 
(d) film series; and

(e) meetings of study groups to discuss specific topics. ${ }^{37}$

\section{Lecture Method}

The lecture method of instruction is concerned with the transmission of information, and has been described as the, "transfer of material from the teacher's notes to the students notes without passing through the minds of either." ${ }^{38}$ The lecture method has also been described as "non-involvement, non-experiential, non-interest arousing and nonsense as a method of teaching professional responsibility."39

The method is acknowledged as being a useful method for the conveying of an understanding of philosophical arguments as they specifically relate to the ethical dilemmas of lawyers, and for the conveying of "black letter" ethics law (for example, the applicable rules or codes of conduct).

However, the lecture method is not useful as an educational tool in fostering understanding of a lawyer's personal responsibility for his or her own actions, nor is it useful for enhancing a lawyer's analytical ability. ${ }^{40}$

\section{TIMING}

Depending on the preferred form of instruction, the timing of instruction in legal ethics may not be an issue. If the preferred method of instruction is the pervasive technique, then instruction in legal ethics will occur throughout law school studies.

If, however, a clinical or simulated practice method of instruction is preferred, it must be determined whether the instruction is to occur during a student's law school education, or subsequently perhaps immediately before entry into the profession. Simulated client instruction could, if desired, occur throughout law school, since the simulations could be tailored to fit in with the student's stage of instruction in substantive law. The timing is less clear with clinical education, since a student's knowledge of substantive law would have to be well advanced before that student would be equipped to cope with the range of cases that may be presented in a clinical situation.

The greatest debate about timing revolves around teaching of 
single courses in legal ethics. Some existing courses which are intended to explore legal ethics issues are introductory law courses, taught in a student's first year of law school. First year students may lack the basic knowledge to grasp the issues being presented to them, and will not have the perspective necessary to place ethics issues in their wider context. If legal ethics instruction occurs at a later stage, students may be too cynical to give the course the attention it deserves, or may be preoccupied by other courses they perceive to be more important, or preoccupied by the prospect of finding employment. Instruction at a later stage of legal education may, of course, mean that students lacked the necessary background knowledge to recognise and raise issues of legal ethics as they arose in other earlier courses. ${ }^{41}$

\section{VOLUNTARY OR COMPULSORY INSTRUCTION}

Experience in Canada suggests that if instruction in legal ethics is voluntary, not many students elect to take such courses. ${ }^{42}$ On the assumption that teaching legal ethics:

shares a number of goals with the teaching of any other law field; teaching analytical thinking skills, constructing an analytical framework for the examination of problems that arise in the field, conveying a block of substantive law, and providing an academic atmosphere for critique of the current state of knowledge in the field ${ }^{43}$

there seems little reason why instruction in legal ethics should not be compulsory. As one leading advocate of compulsory teaching in legal ethics has stated:

Professional schools should require instruction for the same reason that they require courses in other areas; the subject is central to effective practice and not all students will elect it. Historical experience demonstrates that a laissez-faire approach is particularly inadequate when it comes to ethics. Many student wish to avoid anything that appears "touchy-feely." A well-constructed ethics curricula, however, addresses issues of far more personal relevance than much of what is now required in professional schools. Many practising lawyers will never encounter a shifting (or springing) use; virtually all will confront issues of honesty, confidentiality, and loyalty. Only through mandatory curricular offerings can we reach students who are least likely to elect coverage and often most in need of exposure. ${ }^{44}$ 


\section{PROPOSED OR EXISTING COURSE STRUCTURES}

\section{Coordinated Curriculum for Legal Education in Canada}

A "coordinated curriculum" has been devised by Brent Cotter as a result of his recent study of the teaching of legal ethics in Canada. This "coordinated curriculum" prescribes the preferred course structure for the teaching of legal ethics during law school, after law school but before admission, and throughout the lawyer's professional life. The approach: it is suggested, will ensure a continuum in law schools, bar admission programmes and continuing education curricula in which there will be opportunities at increasing levels of sophistication to probe complex issues faced by lawyers in the modern world. ${ }^{45}$

Cotter has devised a series of aims for instruction in legal ethics. He has formulated a "building block" approach to achieving these aims, recognising that the education should be a gradual process, with instruction tailored to achieving the appropriate standard of education at the appropriate stage in that education. ${ }^{46}$

Legal ethics instruction at Law School: Cotter recommends that there be both pervasive instruction and "stand-alone" instruction in legal ethics during law school. He favours a course structure along the lines of the following.

In the first term of first year, a course dedicated to an introduction to the legal profession and to the roles of lawyers within the legal profession, emphasising:

- the relationship between the law school and professional responsibility

- the predominant features of the profession including its independence, self-government and the monopoly in the delivery of legal services

- the various obligations associated with these features of the profession

- the roles of lawyers and conflicts which can arise in carrying out these roles

- the sources of these obligations and features of the profession and of lawyers' professional roles, examined from different perspectives.

In other first year courses there should be a coverage of issues 
related to the legal profession and legal ethics. There should be coordination of this instruction with the block instruction.

There should be supporting materials available which are appropriate to the subject matter of the course. Such materials should emphasize the general learning objectives of the course and the relationship between the ethics issues and the course in which the issue arises.

First year instruction should involve students in small group activities, should encourage discussion with and among students and should use a variety of teaching methodologies.

Assessment of a law student's first year performance should include an assessment of the legal ethics aspects of the courses which have been taught.

In the later years of law school, legal ethics instruction should be conducted using the pervasive technique. It should recognize and supplement the instruction received during first year, and should offer a wide array of and broad exposure to educational experiences in legal ethics. Clinical courses should also be given high priority.

In addition, there should be a further "stand-alone" course preferably in the third year of law school which would:

- bring together and build upon previous relevant instruction;

- develop analytical frameworks for the resolution of ethical dilemmas;

- engage in analysis and critique from a variety of perspectives; and

- address the relationship between professional attitudes and values.

This course would ideally be taught in small groups, and students should be encouraged to be personally engaged in the learning process. Teachers should be prepared to experiment with innovative teaching methodologies and the course should be assessed in the same manner as other courses.

Legal ethics instruction During Bar Admission Programmes: at this stage in a student's legal education, Cotter advocates that any further instruction should be directed at

(a) the rules, roles and responsibilities of the legal profession and lawyers;

(b) the identification and resolution of ethical dilemmas; and 
(c) law office economics and management.

Legal ethics instruction should be provided in practical terms and should assume an academic understanding of legal ethics issues and analytical frameworks, and build upon this understanding in practical ways.

In relation to (a), instruction should emphasize the doctrinal aspects of legal ethics, that is, the organisational and regulatory structure of the profession in the jurisdiction, the law relevant to the profession and the rules of conduct for lawyers in the jurisdiction. In relation to (b), instruction should take place in the context of simulated files and transactions commonly experienced by junior lawyers. The legal ethics issues embedded in the files and transactions should be selected in consultation with senior practitioners and with reference to empirical findings regarding the types of ethical dilemmas commonly experienced by junior lawyers in practice.

Evaluation of pre-admission instruction in legal ethics should be by way of assessment of ability to identify and resolve legal dilemmas. Criteria for assessment should be identified, and would ideally include the following:

- identification of the issues embedded in the simulated events and transactions;

- resolution of these issues within the range of acceptable courses of action.

It is important that there be clear articulation of evaluation criteria to students.

Legal ethics instruction during Articling: Cotter sees the need for continued education in legal ethics after the completion of formal pre-admission education. Such education should emphasise the opportunity to observe and learn about the role of the legal profession and the roles of lawyers and about ethical dilemmas in practical contexts. The programme of instruction should be relevant to the kinds of dilemmas faced by young lawyers. Cotter believes evaluation at this stage should be limited only to those students who demonstrate consistent failure to follow appropriate ethical guidelines.

Legal ethics instruction during Continuing Legal Education ("CLE”). Cotter believes that there should be "general", "advanced" and "remedial" programmes within the CLE 
curriculum as it relates to issues of legal ethics. Providers of CLE should undertake investigations to determine which issues and methodologies are most appropriate for inclusion within the CLE curriculum, and should design appropriate instructional seminars, and participate in the design of legal ethics elements of remedial seminars.

There are two possible structures or CLE courses in legal ethics:

- legal ethics as a specific focus of CLE; and

- legal ethics taught pervasively.

Cotter suggests that specific courses in legal ethics will be unpopular and may fail to attract many participants.

The purpose of instruction in legal ethics in CLE courses at a basic level is to acquaint practitioners with their basic ethical obligations and the context in which they arise, and to inform them of recent developments relevant to the legal profession and their work as lawyers. Instruction at an advanced level should be designed to enable practitioners to identify and resolve ethical issues relevant to specialised areas of law, and to incorporate this resolution process into their general framework of ethical decision making.

\section{Comprehensive Skills Development Programme}

A comprehensive skills development programme is currently being taught at the Marshall-Wythe School of Law, College of William and Mary. ${ }^{47}$ The programme consists of courses designed to teach skills ranging from research and writing and trial advocacy to "recognising and thinking cogent thoughts about ethical problems and ... obtaining interpersonal skills to enable the execution of carefully thought out plans to resolve ethical

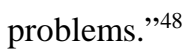

The programme is taught over four semesters and has the following as its goals:

1 the imparting and development of necessary legal skills;

2 the sensitizing of students to the ethical issues they will face as lawyers; and

3 the augmentation and reinforcement of more traditional academic approaches.

The legal skills course covers the following topics:

- history and structure of the legal profession; 
- professional ethics;

- legal research;

- legal writing;

- legal drafting;

- interviewing;

- negotiating;

- counselling;

- alternative dispute resolution;

- pre-trial practice;

- introduction to trial practice; and

- introduction to appellate practice.

The programme proceeds on concurrent tracks - classroom instruction and simulated practice. The programme has as its core client representation, consequently the entire programme is organised around a simulated student law office and its need to deliver effective competent and ethical service.

Course instruction includes components such as reading assignments, class meetings of several varieties (large group and small group), activity critiques, written work critiques, panel discussions and interaction between second year students and first year students.

The course is graded on both a letter grade system and an honours/pass/fail system. Students failing a semester of legal skills may not continue in the programme until they successfully complete the failed semester. Progress is evaluated by examining the quality of the student's performance of all assignments, activities and responsibilities during the semester.

In the legal skills course ethics is not treated as a "side" topic but rather permeates throughout the programme's two years' of operation. Issues of legal ethics are approached from a wide variety of perspectives including the following:

1 Experiential exposure to ethics - this is the treatment of legal ethics issues within the context of simulations. The treatment of ethics in this context "changes the simulations from mere competitive games, to much truer, better textured representations of clients service." ${ }^{49}$

2 Readings - sources include the model code of professional conduct and model rules of professional conduct (Bellow and Moulton, The Lawyering Process, Ethics and Professional 
Responsibility), cases and materials compiled by the faculty as well as newspaper and magazine articles that raise pertinent issues.

3 Classroom discussion - weekly simulated "office" meetings frequently have aspects of legal ethics to them and, in addition, relatively large group sessions on ethics/legal profession issues take place. Large group sessions are used to ensure that all topics that would have been covered in the traditional free-standing legal profession course are covered and to provide opportunity for academic discussion of the topics to which students were exposed by the simulated client practice over the two years of the programme.

$4 \quad$ Written work - students produce a number of short writings regarding ethics questions at the request of their supervisors during the two years of their course. Students are also required to produce a short ethics-related writing assignment.

5 Exposure to faculty role models - during the simulations students work for a member of faculty who assumes the role of senior partner. In addition students observe the work of other offices' senior partners.

6 Disciplinary processes - students are exposed early on to the importance of maintaining high standards of professionalism. The simulated programme has a disciplinary process in place to deal with complaints of conduct which violate the model code or model rules.

7 Comprehensive simulation - students see the results of each activity in which they engage and consequently learn more about that particular activity. In the simulated client situation:

Unlike ethics teaching in isolated activities such as negotiation or interviewing exercise that appears and as quickly disappears, students deal with a single individual in the role of client, another in the role of adverse party, others in the role of adverse counsel, others in the role of co-counsel and still others in the role of court personnel for up to two years from the beginning to the closing of the case. As such, a relationship poorly begun must be repaired; unethical behaviour of fellow members of the bar must be reported under appropriate circumstances; and consequences of lawyering conduct are realized ... In the program students by dealing with the clients from beginning to end have greater opportunities for reflection on the ultimate lawyer ethics questions that arise only through experiencing long term the daytoday activities and relationships of lawyering. ${ }^{50}$ 
Although the course has been in place for a limited time the faculty administration is happy with the way in which the course is working so far. The structure has apparently been well received by students.

\section{Comprehensive Programme - Harvard Medical School Curriculum}

In a recent discussion paper on learning ethics in the Harvard Medical School curriculum the following areas were seen as essential elements of a comprehensive programme emphasising ethics themes:

1 A basic framework for addressing ethical issues.

2 Lectures - covering basic concepts and explicitly underscoring the importance of ethical analysis in the curriculum.

3 Cases - explicitly emphasising ethical issues that are raised in specific cases including guiding questions and background references that support reflection about ethical issues.

4 Reading - core readings related to both conceptual and practical aspects of ethical skills.

5 Practical skills - explicit attention to the skills needed for implementing a planned approach to managing ethical issues.

6 In-depth study.

7 Extra-curricular programmes — organised with societies and the Office of Student Affairs.

8 Faculty development.

9 Evaluation

\section{CONCLUSIONS}

As there are multiple objectives to be achieved in teaching legal ethics it is no wonder that there is little consensus about the approaches, methods and materials that should be used. What is clear is that instruction in legal ethics should not be undertaken with the aim of inculcating particular ethical values in students. Rather, such instruction should aim to sensitize students to the ethical dimensions of practice as a lawyer, provide insight into the nature of the legal profession and cultivate a willingness to engage in reflective judgment. ${ }^{51}$ 
It is important that students are prepared for ethical decision making as they are prepared for any other area of practice, if for no other reason than the fact that ethical issues pervade a practitioner's life. The challenge is in developing a course structure which fulfils the aims and objectives of teaching legal ethics, does not alienate students and importantly provides students with a framework in which to address ethical issues as they arise throughout their professional lives.

* Allen Allen \& Hemsley, Solicitors.

(C) 1993. (1993) 4 Legal Educ Rev 141.

1 WB Cotter Professional Responsibility Instruction in Canada: Coordinated Curriculum for Legal Education (Quebec: Joint National Committee on Legal Education of Federation of Law Societies of Canada and Council of Canadian Law Deans, 1992) 1-6.

2 DL Rhode, Ethics by the Pervasive Method (1992) 42 J Legal Educ 31, at 44.

3 Id at 49.

$4 \quad I d$ at 50.

5 Id at 32.

6 I Johnstone \& MP Treuthart, Doing the Right Thing: An Overview of Teaching Professional Responsibility in Teaching Legal Ethics: a Symposium (1991) 41 J Legal Educ 75.

7 DL Rhode \& D Luban, Legal Ethics (New York: Foundation Press, 1992) 1021.

8 AF Watson, Some Psychological Aspects of Teaching Professional Responsibility (1963) 16 J Legal Educ 1, at 3.

9 Cotter, supra note 1 , at 1.

10 Cotter, supra note 1 , at (ii).

11 Johnstone \& Treuthart, supra note 6, at 88.

12 Cotter, supra note 1 , at 2-36 to 2-37.

13 Rhode, supra note 2, at 52.

14 Id.

15 MZ Johns, Teaching Professional Responsibility and Professionalism in Legal Writing (1990) $40 \mathrm{~J}$ Legal Educ 501 (quoting the Annual Meeting of the American Bar Association, 22 August 1989).

Cotter, supra note 1 , at $242-243$.

17 Johnstone \& Treuthart, supra note 6, at 93.

18 Id.

19 Cotter, supra note 1, at 2-42 to 2-43.

20 JE Moliterno, An Analysis of Ethics Teaching in Law Schools: Replacing Lost Benefits of the Apprentice System in the Academic Atmosphere (1991) 60 Cincinnati L Rev, 83, at 133.

21 Id.

Id.

Id.

Id at 117.

Id at 126-7.

Johnstone \& Treuthart, supra note 6 , at 82.

Watson, supra note 8, at 20. 
Johnstone \& Treuthart, supra note 6, at 98.

Id.

Johnstone \& Treuthart, supra note 6, at 99.

Rhode \& Luban, supra note 7, at 995.

Johnstone \& Treuthart, supra note 6, at 97.

Id.

$I d$.

Id.

Johnstone \& Treuthart, supra note 1, at 100-101.

Id at 96 .

Moliterno, supra note 20, at 106.

Johnstone \& Treuthart, supra note 6, at 97.

40 Moliterno, supra note 20, at 106.

41 Rhode, supra note 2, at 51.

42 Cotter, supra note 1, at 2-20 to 2-21.

43 Rhode, supra note 2, at 43.

44 Id.

45 Foreword to Cotter, supra note l.

46 See generally, Cotter, supra note l, at ch 4.

47 See generally, JE Moliterno, Teaching Legal Ethics in a Program of Comprehensive Skills Development (1990) 15 J Legal Prof 145.

$48 \quad I d$ at 147.

49 Id 163

50 Moliterno, supra note 47, at 166-167.

51 Johnstone \& Treuthart, supra note 6, at 102. 